\title{
Experimental Study of Self-heating Ignition of Lithium-Ion Batteries During Storage: Effect of the Number of Cells
}

\author{
Xuanze He, Department of Mechanical Engineering, Imperial College London, \\ London SW7 $2 A Z, U K$ \\ Francesco Restuccia, Department of Engineering, King's College London, \\ London WC2R 2LS, UK \\ Yue Zhang, State Key Laboratory of Fire Science, University of Science and \\ Technology of China, Hefei 230026 Anhui, China \\ Zhenwen Hu, Department of Mechanical Engineering, Imperial College London, \\ London SW7 2AZ, UK \\ Xinyan Huang, Department of Building Services Engineering, The Hong Kong \\ Polytechnic University, Kowloon, Hong Kong, China \\ Jun Fang, State Key Laboratory of Fire Science, University of Science and \\ Technology of China, Hefei 230026 Anhui, China \\ Guillermo Rein (D), Department of Mechanical Engineering, Imperial College \\ London, London $S W 72 A Z, U K$
}

Received: 28 August 2019/Accepted: 26 June 2020

Abstract. Lithium-ion batteries (LIBs) are widely used as energy storage devices. However, a disadvantage of these batteries is their tendency to ignite and burn, thereby creating a fire hazard. Ignition of LIBs can be triggered by abuse conditions (mechanical, electrical or thermal abuse) or internal short circuit. In addition, ignition could also be triggered by self-heating when LIBs are stacked during storage or transport. However, the open circuit self-heating ignition has received little attention and seems to be misunderstood in the literature. This paper quantifies the self-heating behaviour of LIB by means of isothermal oven experiments. Stacks of 1, 2, 3 and 4 Sanyo prismatic $\mathrm{LiCoO}_{2}$ cells at $30 \%$ state of charge were studied. The surface and central temperatures, voltage, and time to ignition were measured. Results show that self-heating ignition of open circuit LIBs is possible and its behaviour has three stages: heating up, self-heating and thermal runaway. We find for the first time that, for this battery type, as the number of cells increases from 1 to 4 , the critical ambient temperature decreases from $165.5^{\circ} \mathrm{C}$ to $153^{\circ} \mathrm{C}$. A Frank-Kamenetskii analysis using the measured data confirms that ignition is caused by self-heating. Parameters extracted from Frank-Kamenetskii theory are then used to upscale the laboratory results, which shows large enough LIB ensembles could self-ignite at even ambient temperatures. This is the first experimental study of the effect of the number of cells on selfheating ignition of LIBs, contributing to the understanding of this new fire hazard.

\footnotetext{
* Correspondence should be addressed to: Guillermo Rein, E-mail: g.rein@imperial.ac.uk
} 
Keywords: Ignition, Lithium-ion battery, Heat transfer, Thermal runaway, Energy

\section{Introduction}

Lithium-ion batteries (LIBs) are an important type of energy storage device with high specific energy, high power, and a long cycle life. Due to their advantages, LIBs have been widely used for commercial applications, such as laptops, mobile phones and electric vehicles. Because of the fast development of electric vehicle technology and the increasing demand for electric vehicles, the global market of LIBs is predicted to keep increasing to USD 93.1 billion by 2025 [1].

However, LIBs are a new safety hazard because of their tendency to ignite and burn. Many fires resulting in economic losses and casualties have been reported [2]. For example, two LIB fires happened in two Boeing 787 Dreamliners in January 2013 [3]. In 2016, a series of LIB fires of Samsung mobile phones led to a recall of the Galaxy Note 7 around the world leading to a large falloff in sale.

Ignition of LIBs can be triggered by abuse conditions, including mechanical abuse (crushing, penetration), electrical abuse (external short circuit, overcharge), thermal abuse (overheating) or internal short circuit [4]. All of these can initiate thermal runaway leading to fires. Unlike the first three abuse conditions, which require external factors, internal short circuit occurs inside LIB leading to spontaneous ignition. Since the Boeing 787 Dreamliner battery fires reported in 2013 [5], spontaneous ignition of LIBs has been under closer scrutiny. The cause of spontaneous ignition has been thought to be internal short circuit only [4-6], until a recent study found that spontaneous ignition can occur without an internal short circuit but because of internal chemical reactions [7]. Another possibility for spontaneous ignition of LIBs is by self-heating in open circuit condition, particularly when they are stacked forming a large pile in a warehouse or a cargo.

Self-heating is the tendency of certain materials to undergo spontaneous internal exothermic reactions causing an increase in their temperature [8-10]. Self-heating ignition has been studied in many organic materials, such as coal [11], and shale [12]. For large sizes of these materials, self-heating ignition can occur at low ambient temperatures [8,9]. This is because heat generation due to chemical reactions is proportional to sample volume, while heat losses are proportional to sample surface area. Therefore, when the sample size is relatively large, the heat generation rate can be higher than the heat dissipation rate, resulting in spontaneous ignition caused by self-heating [9].

LIB ignition caused by various abuse conditions has been studied at both the small component scale and single-cell scale. By studying the chemical reactions using different combinations of components [13, 14], the reactions of LIB thermal runaway have been identified [15]. In the order of onset temperatures from low to high, these reactions include: SEI (solid electrolyte interphase) decomposition, the reaction of intercalated Lithium with electrolyte, positive active material decomposition and electrolyte decomposition. The kinetics of these reactions have been studied [16] and employed in simulations of a single cell [17]. Tobishima and Yamaki [18] first experimentally studied self-heating ignition of a cylindrical 
$\mathrm{LiCoO}_{2} \mathrm{LIB}$ using oven experiments. After this, the effects of the state of charge (SOC) [19], cathode materials [20] and aging process [21] on this onset temperature were investigated. In terms of spontaneous ignition of LIBs, the internal short circuit issue has been considered [4-6]. The formation and detection of the internal short circuit, and how it causes spontaneous ignition are three key research topics [22-24]. Once the internal short circuit happens, the temperature of LIBs increases rapidly because of joule heating. The temperature increase triggers the chemical reactions, leading to spontaneous ignition [4]. Some works [25-27] have studied the critical self-ignition temperature of a single cell using non-dimensional analysis based on self-heating ignition theories. However, as only one cell was used in previous experiments [13-27], the number of cells and the consequent effects of heat transfer were neglected. The ignition of a LIB box has been numerically investigated by $\mathrm{Hu}$ et al. [28]. Results show that insulating materials could decrease the critical temperature of self-heating ignition, because these materials reduce the heat dissipation of cells.

When multiple are cells stacked together during storage or transport, the critical self-heating ignition temperature could be lower than the temperature for one cell. We attempt to show the key symptom of self-heating, which is the ignition temperature decreases as the number of cells increases. This unique symptom proves the possibility of self-heating ignition of LIBs.

In order to verify if LIB fires can start by self-heating, isothermal oven experiments for bench-scale samples are recommended [8]. Other faster methods employed in LIB ignition investigations include differential scanning calorimetry (DSC) [29], C80 micro-calorimeter [14], vent sizing package 2 (VSP2) adiabatic calorimeter [29] and Copper Slug Battery Calorimeter (CSBC) [30]. These methods are used to study component scale or single-battery scale. Accelerating rate calorimetry (ARC) [16] is another method to investigate self-heating for benchscale samples in an adiabatic environment, which does not consider heat transfer among samples. Additionally, considering the low onset temperature of self-heating and low reaction rate of self-heating reactions $[8,31]$, the kinetics obtained by these methods do not correspond to the kinetics of slow self-heating ignition. In comparison, an oven is large enough to conduct bench-scale samples and can provide constant temperature heating to study the heat transfer effects.

In the current study, for the first time in literature, the effect of the number of cells on the self-heating behaviour of $\mathrm{LiCoO}_{2} \mathrm{LIBs}$ at $30 \% \mathrm{SOC}$ has been studied using oven experiments. The effective kinetics and effective thermal properties of LIBs are extracted based on self-heating ignition theory, and are used to predict self-heating ignition of LIBs at real sizes in storage and their dependence on the ambient temperature.

\section{Self-heating Ignition Theory}

The first theory to describe the self-heating phenomenon was put forward by Semenov [8, 31]. This theory assumes a uniform temperature of the system, ignores the consumption of materials and assumes that heat generation is due to 
one global chemical reaction. These assumptions limit the wider utilization of Semenov theory because the temperature profile of most solid materials is not uniform. However, Semenov theory can effectively describe the self-heating problem of liquids.

In order to describe a more realistic temperature distribution of solids, FrankKamenetskii proposed a model that incorporated the heat conduction of Fourier's law $[8,31]$. As the temperature variation of a substance itself can be calculated, Frank-Kamenetskii theory has been widely employed to investigate the characteristics of substance self-heating ignition [12]. This theory also neglects fuel consumption and assumes that heat production is from a global chemical reaction based on Arrhenius law. According to these assumptions, the energy conservation of the Frank-Kamenetskii theory is shown in Eq. (1):

$$
k \nabla^{2} T+f(t) \Delta H_{c} \exp \left(\frac{-E}{R T}\right)=\rho c \frac{\partial T}{\partial t}
$$

where $k$ is the thermal conductivity of the fuel, $T$ is the temperature of the fuel at a location, $f(t)$ is the mass action law that depends on the concentration of reactants at any time, $\Delta H_{c}$ is the effective heat of reaction of the fuel, $E$ is the effective activation energy to describe the global reaction, $R$ is the universal gas constant, $\rho$ is the density of the fuel, $c$ is the heat capacity of the fuel and $t$ is time.

Frank-Kamenetskii theory solves this transient heat conduction equation in steady state, as it assumes both the heat of reaction and effective activation energy of the material are large enough so that a steady state can be reached [9, 12, 31]. In practical cases, this is a well-approximated assumption as the temperature of the material is stable before ignition [12]. As a result, the right-hand side of the Eq. (1) is equal to zero.

To solve Eq. (1) at steady state, Frank-Kamenetskii defined a dimensionless heat generation number of $\delta[8,31]$, which is also known as the Damkohler number, shown in Eq. (2):

$$
\delta=\frac{E L^{2} f_{0} \Delta H_{c}}{k R T_{a}^{2}} e^{-E /\left(R T_{a}\right)}
$$

where the $L$ is the characteristic length, $T_{\mathrm{a}}$ is the ambient temperature, $f_{0}$ is the value of mass action law at initial time, which is a constant as the consumption of materials is ignored. As can be seen, $\delta$ increases as the characteristic length $L$ increases or as the ambient temperature $T_{\mathrm{a}}$ increases.

Frank-Kamenetskii theory find that when $\delta$ is higher than a critical value $\delta_{c}$, thermal runaway occurs leading to ignition $[8,31] . \delta_{c}$ is only related to the geometry of substance when the boundary condition $T=T_{a}$ can be satisfied. This boundary condition is easy to reach when convection is large. The values of $\delta_{c}$ can be found in literatures [8,31], for example, its value for an infinite slab is 0.878 , and for a cube is 2.52 . In this study, prismatic batteries have been used to study LIB self-heating ignition, the geometry of LIBs can be regarded as a cuboid. 
The $\delta_{c}$ value of a cuboid is not a constant but depends on the length of the three sides. $\delta_{c}$ can be calculated using the rectangular brick equation [8], which is shown in Eq. (3):

$$
\delta_{c}(a, b, c)=0.84\left(1+1 /(b / a)^{2}+1 /(c / a)^{2}\right)
$$

where $a, b, c$ is the half length of three sides with relation of $a<b, c$.

At critical ignition condition, the dependence of the critical ambient temperature can be obtained by rearranging Eq. (2) at critical ignition condition, and taking the logarithm, as shown in Eq. (4):

$$
\ln \left(\frac{\delta_{c} T_{a, c}^{2}}{L^{2}}\right)=\ln \left(\frac{E}{R} \frac{f \Delta H_{c}}{k}\right)-\frac{E}{R} \frac{1}{T_{a, c}}
$$

where $T_{\mathrm{a}, c}$ is the minimum ambient temperature in which the ignition of the given sample size will occur.

By plotting the $\ln \left(\frac{\delta_{c} T_{a, c}^{2}}{L^{2}}\right)$ against $\left(\frac{1}{T_{a, c}}\right)$, a straight-line correlation can be obtained if the one-step global Arrhenuus reaction assumption is appropriate to apply to LIBs, which shows self-heating ignition can be modelled by FrankKamenetskii theory. The slope of the straight line is $-\frac{E}{R}$, while the intercept corresponds to $\frac{E}{R} \cdot \frac{f \Delta H_{c}}{k}$. Thus, the effective kinetics and thermo-physical parameters can be acquired.

\section{Materials and Methods}

\subsection{LIB Samples}

Sanyo UF103450P prismatic batteries with graphite anode and $\mathrm{LiCoO}_{2}$ cathode were selected for experiments, due to their widespread use in consumer electronics and ease of purchase. The cell has a nominal voltage of $3.7 \mathrm{~V}$ and nominal capacity of $1880 \mathrm{mAh}$, with the dimension of $34 \mathrm{~mm} \times 10 \mathrm{~mm} \times 50 \mathrm{~mm}$. Each cell has a burst disc as a safety vent on the positive side. When the internal pressure is higher than a threshold, this safety venting will release gases.

The state of charge (SOC) of $30 \%$ was selected for the experiments, as this is the maximum SOC allowed when batteries are shipped by air according to the Packing Instruction 965 (UM 3480) by IATA. Before the experiments, in order to measure the actual electrical capacity and ensure the same SOC, each cell was cycled three times at $0.2 \mathrm{C}$ rate for $5 \mathrm{~h}$ at each charge or discharge process, with the final cycle to $30 \%$ SOC. After this, cells were rested for $5 \mathrm{~h}$ to avoid internal heat effects due to cycles.

\subsection{Experimental Methods}

The experimental setup employed to determine the critical minimum ambient temperature for self-heating ignition of LIB cells was based on the procedure in the 

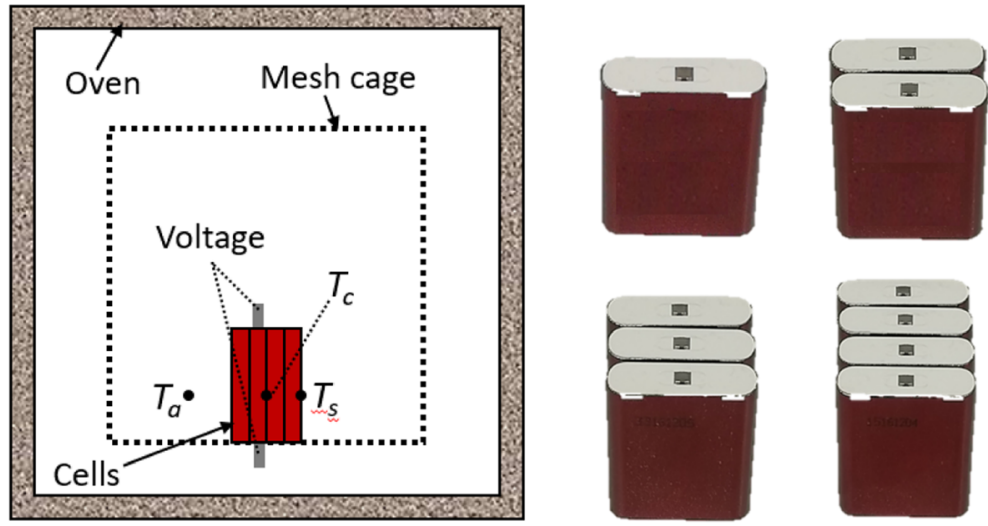

Figure 1. Experimental setup for studying self-heating ignition of $30 \%$ SOC cells. Cells were placed at the centre of a metal mesh cage in a mechanically ventilated $136 \mathrm{~L}$ oven, attached thermocouples for measuring the ambient $\left(T_{a}\right)$, centre $\left(T_{c}\right)$ and surface $\left(T_{s}\right)$ temperatures and connected wires to measure voltage. The error of ambient temperature is $\pm 1^{\circ} \mathrm{C}$ due to the error of the thermocouple. The four stacks used for experiments are shown at the right side.

British Standards EN 15188:2007. Figure 1 shows the overall experimental setup for studying self-heating ignition of cells with a different number of cells. Stacks of $1,2,3$ and 4 cells were selected. Cells were stacked into a cuboid using wires around them to fix the shape, as this shape is easy to stack, to calculate $\delta_{c}$, and to ensure the internal conductive heat transfer. The physical dimensions of the different number of cells are shown in Table 1 to illustrate how they were stacked. According to Eq. (3), $\delta_{c}$ and $\delta_{c} / L^{2}$ are calculated and shown in Table 1, which demonstrates that as the increase of the number of cells, $\delta_{c} / L^{2}$ decreases, and $\delta_{c}$ increases. $B i$ numbers $\left(B i=\frac{h_{c} L}{k}\right)$ are evaluated and shown in Table 1 to determine whether the lumped capacitance method can be used [32], and justify which selfheating ignition theory should be chosen [8]. The heat transfer coefficient $h_{c}=11$ $\mathrm{W} / \mathrm{m}^{2} \mathrm{~K}$ is calculated from the experimental results (see Sect. 4.3). The effective conductivity of LIB $k=1.08 \mathrm{~W} / \mathrm{m} \mathrm{K}$ was previously measured experimentally in [33] for $\mathrm{LiCoO}_{2}$. The characteristic length $L$ is half the length of the smallest side.

\section{Table 1}

Physical Dimensions of Cells at Different Sizes, and Their $\delta_{c}, \delta_{c} / L^{2}$, Bi

\begin{tabular}{lcccccc}
\hline Number & Width (a) (mm) & Length (b) $(\mathrm{mm})$ & Height (c) $(\mathrm{mm})$ & $\delta_{c}$ & $\delta_{c} / L^{2}$ & Bi \\
\hline 1 & 10 & 34 & 50 & 0.946 & $37,850.57$ & 0.051 \\
2 & 20 & 34 & 50 & 1.265 & $12,650.57$ & 0.102 \\
3 & 30 & 34 & 50 & 1.796 & 7983.91 & 0.154 \\
4 & 40 & 34 & 50 & 1.835 & 6350.57 & 0.209 \\
\hline
\end{tabular}


If $B i<0.1$, the thermal resistance and the temperature gradient of cells are negligible, and therefore the lumped capacitance assumption can be employed [8] and the Semenov theory should be chosen [32]. Otherwise, when $B i>0.1$, the lumped capacitance method is not satisfied [8], and the Frank-Kamenetskii theory should be selected [32].

Cells were placed at the centre of a metal mesh cage in a thermostatically controlled $136 \mathrm{~L}$ oven, which has mechanically forced air circulation to prevent thermal stratification. Cells are strapped and fastened together using fine wires to fix the geometry and keep cells in contact with each other. This helps avoid the effect of thermal contact resistance due to swelling. Three thermocouples were employed to measure temperatures: one at the surface of the central cell $\left(T_{c}\right)$, the second attached on the surface of one of the outmost cells $\left(T_{s}\right)$, and the third used to monitor the ambient temperature $\left(T_{a}\right)$. In order to monitor the voltage history during experiments, one of the central batteries was welded with nickel strip on both terminals, which were connected to the cycler using high-temperature resistant wires. The metal mesh cage was used to reduce the effects of airflow on results, and to prevent the fires and projectiles destroying the oven.

The minimum critical temperature, $T_{\mathrm{a}, c}$, is defined as the minimum ambient temperature that allows thermal runaway to happen causing ignition. When conducted an experiment, if cells failed to ignite, the experiment was repeated with fresh cells at a $10^{\circ} \mathrm{C}$ higher temperature. If cells reached ignition, the experiment was repeated with fresh cells at a $10^{\circ} \mathrm{C}$ lower temperature. The experiments were conducted until $T_{\mathrm{a}, c}$ was identified with the maximum error of $\pm 5^{\circ} \mathrm{C}$ for each number of cells. Then, the critical temperature experiments were repeated twice to decrease the error range. The total experiments carried out are summarised in Table 2. In total, 35 experiments corresponding to $158 \mathrm{~h}$ of oven run time were conducted.

\section{Results and Discussion}

\subsection{Self-heating Ignition Phenomenon}

In general, in terms of $\mathrm{LiCoO}_{2}$ cells at $30 \% \mathrm{SOC}$ in our experiments, their selfheating ignition behaviours can be summarized into the following three stages: heating up, self-heating and thermal runaway. Taking a 1-cell experiment at $173^{\circ} \mathrm{C}$ as an example, Fig. 2 presents its three-stage self-heating ignition phe-

\section{Table 2}

Total Number of Experiments Carried Out for the Different Number of Cells

\begin{tabular}{lrrrr}
\hline Number of cells & 1 & 2 & 3 & 4 \\
Number of experiments & 15 & 7 & 6 & 7 \\
\hline
\end{tabular}




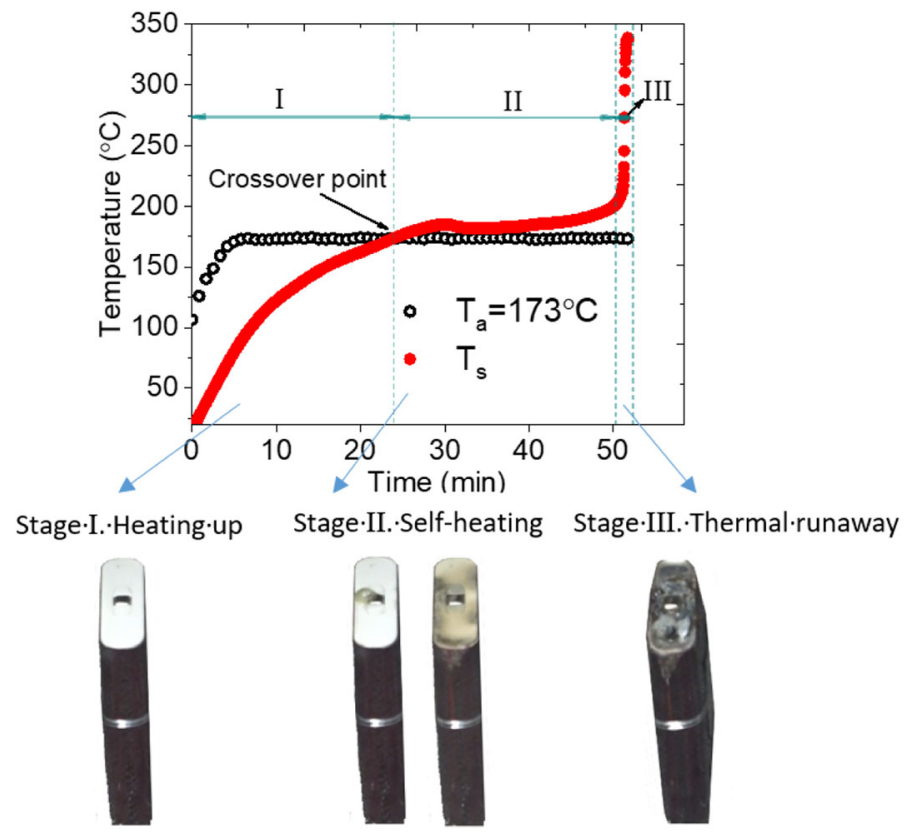

Figure 2. Three stages of $30 \%$ SOC 1 -cell self-heating ignition phenomenon and corresponding temperature and voltage characteristics at the ambient temperature of $T_{a}=173^{\circ} \mathrm{C}$. The typical LIB appearances in different stages are also shown, including cell swelling, electrolyte leakage, self-heating, and thermal runaway.

nomenon and corresponding temperature profile. Table 3 also shows the criteria and observation of the three stages.

\section{Stage I: Heating up}

The first stage starts when a cell is heated significantly above its initial temperature once it has been placed into the oven. The cell temperature increased from the ambient temperature to oven temperature. In all experiments, cells initially began slightly swelling from their middle wall, due to thermal expansion. Once the temperature was higher than the onset temperature of SEI decomposition, this reaction started to generate gases, leading to the further swelling of cells For the experiments when $T_{a} \gg T_{a, c r}$, electrolyte leakage was observed in this stage.

\section{Stage II: Self-heating}

The second stage is characterised by the sample temperature exceeding the ambient temperature. As there is not a significant temperature increase in this stage, no obvious swelling was observed. Additionally, electrolyte leakage was often observed in this stage, in which the electrolyte began to leak out from the 


\section{Table 3}

Criteria and Observations of the 3 Stages in Self-heating Ignition

\begin{tabular}{|c|c|c|}
\hline Stage & Criteria & Observation \\
\hline $\begin{array}{l}\text { I. Heating } \\
\text { up }\end{array}$ & $\begin{array}{l}T_{c} \text { increases significantly } \\
\text { above its initial temperature }\end{array}$ & $\begin{array}{l}\text { (1) Slight swelling } \\
\text { (2) Fast } T_{c} \text { increase } \\
\text { (3) Slow Voltage decrease and rapid fluctuations (1st } \\
\text { drop) } \\
\text { (4) Electrolyte leakage, if } T_{a} \gg T_{a, c r}\end{array}$ \\
\hline $\begin{array}{l}\text { II. Self- } \\
\text { heating }\end{array}$ & Crossover: $T_{c}>T_{a}$ & $\begin{array}{l}\text { (1) No obvious swelling } \\
\text { (2) Electrolyte leakage } \\
\text { (3) Colour of cathode gradually changes from white to } \\
\text { yellow } \\
\text { (4) Crossover: } T_{c} \text { increases over } T_{a} \text {, followed by a slight } \\
\text { drop, and a very slow increase } \\
\text { (5) } 2 \text { nd voltage drops to zero and then recovers }\end{array}$ \\
\hline $\begin{array}{l}\text { III. Ther- } \\
\text { mal run- } \\
\text { away }\end{array}$ & $T_{c}$ increases sharply & $\begin{array}{l}\text { (1) Rapid swelling in } 2-3 \mathrm{~s} \\
\text { (2) Plastic coating near cathode melting } \\
\text { (3) No further colour change at cathode } \\
\text { (4) Venting }\left(T_{a}>T_{a, c r} \text {. ) and smoke. No flare, no fire and }\right. \\
\text { no sparks observed in any of our experiments } \\
\text { (5) } T_{c} \text { fast increase } \\
\text { (6) 3rd voltage drop to zero }\end{array}$ \\
\hline
\end{tabular}

positive side, where there is a safety vent. This leakage leads to the gradual colour change of the cathode from white to yellow. The temperature increases over the ambient temperature due to self-heating, followed by a slight decrease because of the heat losses caused by the electrolyte leakage. After this, the cell temperature started to increase very slowly. When the electrolyte leakage was over, the cell appearance did not change further, but its temperature kept increasing. The heat accumulation in this stage maybe due to the SEI decomposition, reaction of intercalated Lithium with electrolyte, cathode positive material decomposition [4, 15], or the chemical cross over between anode and cathode [7].

\section{Stage III: Thermal runaway}

As the cell temperature increased, thermal runaway happened leading to ignition. The cell rapidly swelled in $2-3 \mathrm{~s}$, due to the fast internal gas generation. When the internal pressure exceeded the threshold, venting happened, as the stage III image shown in Fig. 2. Some smoke can be seen, but no flare, fire or sparks were observed during all experiments.

Moreover, for the first time in the literature, we find that self-heating ignition does not always cause venting. As shown in Fig. 3 of cell images after experiments, when the ambient temperature decreased to $169^{\circ} \mathrm{C}$ for a 1 -cell experiment, the cell self-heating ignition was also captured based on the temperature profile, 


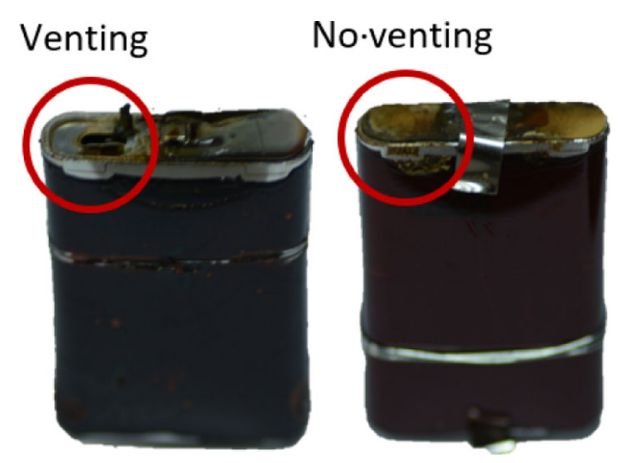

\section{Figure 3. Cell images after experiments. Both thermal runaway and venting happened at $T_{a}=173^{\circ} \mathrm{C}$ (left), but thermal runaway happened at $T_{a}=169^{\circ} \mathrm{C}$ without venting (right). This is the first time the occurrence of LBB thermal runaway due to self-heating without venting was found in the literature.}

but no venting happened. In all our experiments, the ignition without venting only happened in 1-cell and 2-cell experiments at their critical ignition temperature.

In order to fix the shape of stacks and keep cells in contact with each other, wires were used to fasten cells in all experiments. This method caused venting to happen prior to thermal runaway for 3-cell and 4-cell experiments, as wires limit the swelling of cells causing external pressure on the cell surface. Heat and mass losses due to the venting add an additional source of uncertainty to the experiments, but according to the critical temperatures we obtained, these losses do not affect results significantly. Without the fastening of cells using wires, self-heating ignition of 3-cell and 4-cell experiments did not happen even at 2-cell critical ambient temperature. This is because the swelling of cell makes its surface curved, decreasing the physical contact areas between the cells reducing heat transfer, and therefore the cells do not behave as one body. Additionally, in terms of 1-cell and 2-cell experiments, because of small deformation and swelling in total, the wire fastening did not affect experiments in any visible way.

\subsection{Temperature}

Figure $4 a, b$ shows an example of ignition and no-ignition of a 1 cell configuration to explain how to identify $T_{\mathrm{a}, c}$ using temperature data. Cells failed to be ignited at an ambient temperature of $162^{\circ} \mathrm{C}$, but succeed to reach ignition at an ambient temperature of $169^{\circ} \mathrm{C}$. In terms of the no-ignition cases, the cell temperature slightly exceeds the oven temperature firstly, and then it is cooled down to the oven temperature. This is because this oven temperature is the highest subcritical ambient temperature, however, heat generation due to chemical reaction in proportion to sample size is still slightly lower than heat losses proportion to sample surface. Regarding the ignition case, thermal runaway occurs at 106 min indicating the cell has ignited at the oven temperature of $169^{\circ} \mathrm{C}$, which is the lowest 


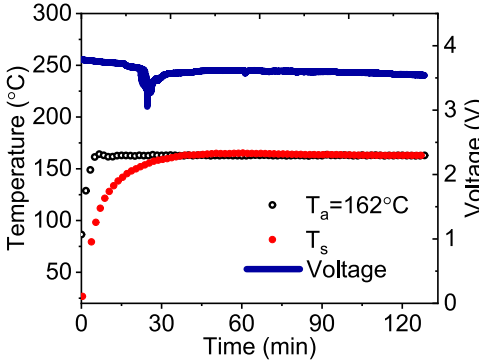

(a) 1 -cell experiment at $T_{\mathrm{a}}=162^{\circ} \mathrm{C}$

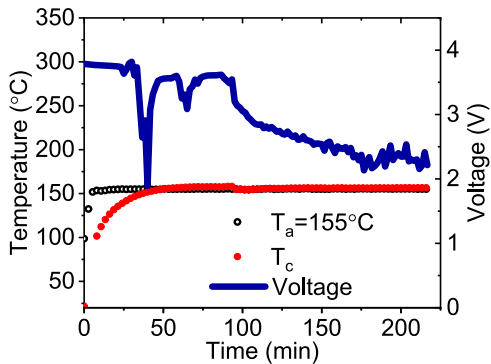

(c) 2-cell experiment at $T_{a}=155^{\circ} \mathrm{C}$

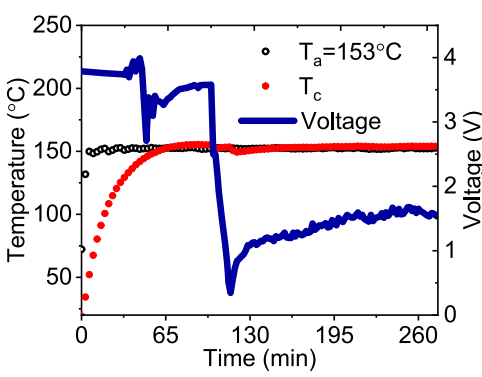

(e) 3-cell experiment at $T_{a}=153^{\circ} \mathrm{C}$

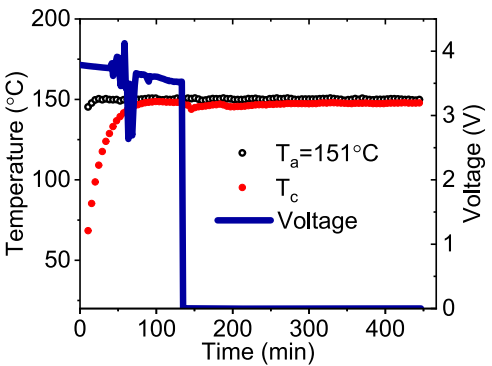

(g) 4-cell experiment at $T_{a}=151^{\circ} \mathrm{C}$.

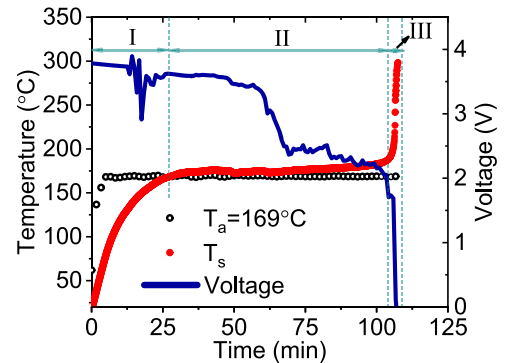

(b) 1 -cell experiment at $T_{a}=169^{\circ} \mathrm{C}$

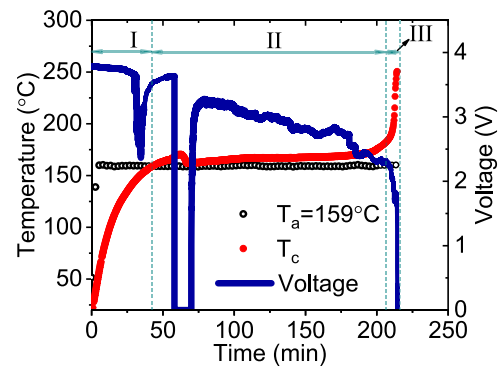

(d) 2-cell experiment at $T_{a}=159^{\circ} \mathrm{C}$

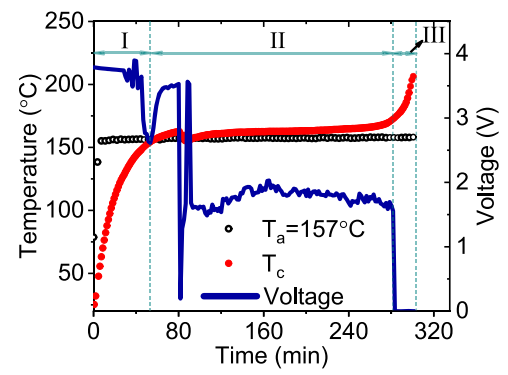

(f) 3-cell experiment at $T_{a}=157^{\circ} \mathrm{C}$

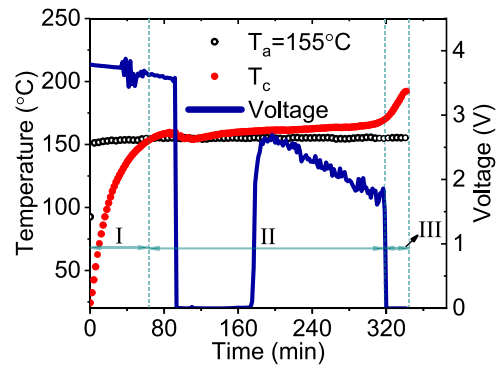

(h) 4-cell experiment at $T_{\mathrm{a}}=155^{\circ} \mathrm{C}$ 
4 figure 4. The temperature and voltage of $1-4$ cells at $30 \%$ soc experiments for both critical ignition and no-ignition cases. The left column is the cases of the maximum ambient temperatures for noignition, while the right column is the cases of the minimum ambient temperatures for ignition for 1-4 cells. The temperature for 1 cell is surface temperature $T_{s}$, and other temperatures are central temperature (the temperature between two central cells) $T_{c}$.

supercritical ambient temperature. Therefore, the $T_{\mathrm{a}, c}$ of the 1 cell is $165.5 \pm 3.5^{\circ} \mathrm{C}$.

The experiments of the maximum ambient temperatures for no-ignition (left) and the experiments of the minimum ambient temperatures for ignition (right) among 1-4 cells are shown in Fig. 4. As the number of cells increases, the peak cell temperature and the minimum ambient temperature for ignition decreases. Additionally, according to the ignition cases in Fig. 4, the cell surface temperature in self-heating stage is equal to the ambient temperature, $T_{s}=T_{a}$, which satisfies the boundary condition of Frank-Kamenetskii theory.

The time to thermal runway, and the times of stage I and II are shown in Fig. 5. The time to thermal runaway equals to the sum of times of stage I and II. As the number of cells increases, the time of stage I increases linearly, while the time of stage II and the time to thermal runaway increase non-linearly.

\subsection{The Heat Transfer Coefficient}

The effective heat transfer coefficient can be estimated using battery temperature data from the heating up stage in Fig. 4. According to Table 1, only 1 cell and 2

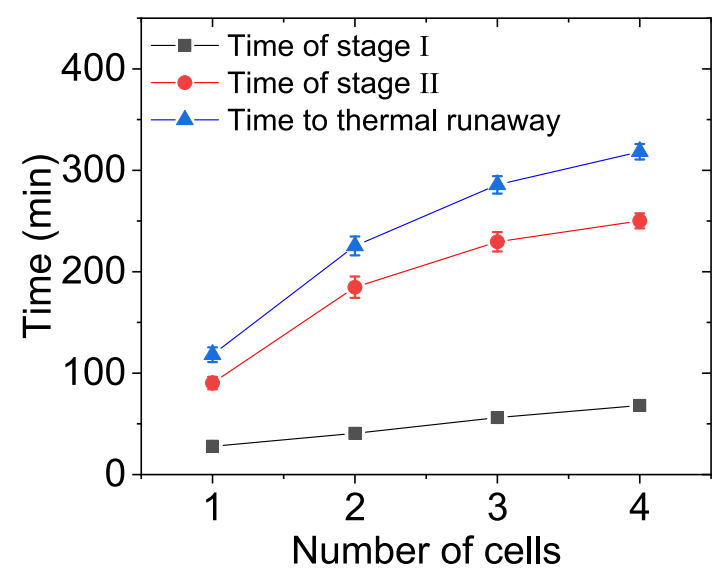

Figure 5. The time to thermal runaway and the times of different stages. The time to thermal runaway is the sum of the time of stages I and II. 
cells have $\mathrm{Bi}<0.1$. In these conditions, based on the lumped capacitance method [32], we have: $\dot{Q}=\operatorname{Sh}\left(T_{a}-T_{s}\right)=m c\left(d T_{s} / d t\right)$, the heat transfer coefficient is $h=m c\left(d T_{s} / d t\right) / S\left(T_{a}-T_{s}\right)$.

Figure 6 presents the plots of $d T_{s} / d t$ vs $T_{a}-T_{s}$ for the critical ignition cases of 1 and 2 cells. The slopes correspond to $h S / m c$, which can be used to extract the heat transfer coefficient. The surface area $S$ is calculated using three side lengths, and the specific heat capacity $c$ is $990 \mathrm{~J} / \mathrm{kg}-\mathrm{K}$ from previous experimental measurements of the same cell [27], and the cell mass $m$ is $36.8 \mathrm{~g}$. Therefore, the heat transfer coefficients of different number of cells can be calculated and are presented in Table 4. The final heat transfer coefficient we selected to calculate Bi number is $11 \mathrm{~W} / \mathrm{m}^{2} \mathrm{~K}$.

\subsection{Voltage}

Figure 4 shows the voltage characteristics across the three stages, and different voltage histories for the no-ignition and ignition cases respectively. In terms of ignition cases, the voltages exhibit similar trends across the experiments. In the first stage, the voltage decreases as the cell temperature increases, because the high temperature can speed up the degradation of cells [34]. There is always a fluctuation followed by the first voltage drop in this stage, which could be a signal of the start of an internal side reaction that is SEI decomposition as this has been regarded as the first side reaction during thermal runaway [4]. Figure 7 gives the time to voltage fluctuation of experiments, and their corresponding cell temperatures at that time. As the ambient temperature increases, the time to voltage fluctuation decreases. This is because it takes a longer time to heat more cells at lower ambient temperature. However, no matter how many cells were used and what the ambient temperature was, the cell temperatures at the time of voltage fluctuation are all around $130^{\circ} \mathrm{C}$, which is close to the onset temperature of SEI decomposition in previous studies $[4,15]$.

In the second stage, the voltage suddenly decreases to zero right after the electrolyte leakage. When the electrolyte leakage finishes, the cell voltage can be detected again in the self-heating stage. Figure 8 gives the relationship between time to electrolyte leakage and time to the 2 nd voltage drop of three 1-cell experiments. Time to electrolyte leakage is defined as when we first observed the electrolyte leakage, and these values were always slightly smaller than time to the 2 nd voltage drop.

After the 2 nd voltage drop, the voltage decreases slowly. This may be caused by anode and cathode side reactions in high-temperatures, which could increase internal resistance by continuing to consume intercalated Lithium, generating further gases and impurities [4].

In the third stage, when the temperature starts to increase rapidly, the voltage sharply decreases to zero again, which can be regarded as a signal that the cell has ignited. 

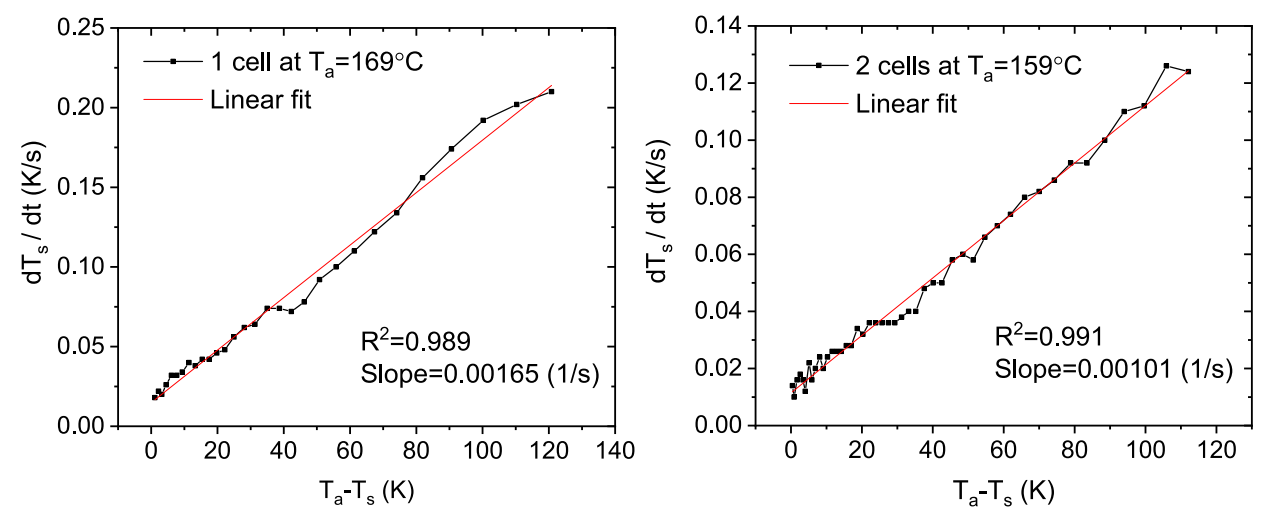

Figure 6. Extracting the heat transfer coefficient $h$ from plots of $d T_{s} /$ df vs $T_{a}-T_{s}$, taking the cases of 1 cell (left) and 2 cells (right). The slopes are proportional to $h$.

\section{Table 4}

Heat Transfer Coefficient for the Different Number of Cells

\begin{tabular}{lll}
\hline Number of cells & 1 & 2 \\
Heat transfer coefficient $\left(\mathrm{W} / \mathrm{m}^{2} \mathrm{~K}\right)$ & 11.83 & 10.89 \\
\hline
\end{tabular}

\subsection{Critical Ignition Temperature}

Based on the ambient temperature data in Fig. 4, the critical temperatures of cell self-heating ignition are identified. The temperature values of $1,2,3$ and 4 cells are $165.5 \pm 3.5^{\circ} \mathrm{C}, 157 \pm 2^{\circ} \mathrm{C} 155 \pm 2^{\circ} \mathrm{C}$ and $153 \pm 2^{\circ} \mathrm{C}$, respectively.

In this work, a clear trend is shown, namely that the required ambient temperature for cell self-heating ignition decreases as the number of cells increases due to the heat transfer effects presented in the theory section. This trend should be satisfied not only for the prismatic cells used here, but also for any other shape of cells, such as cylindrical cells. This is because although the conductive contact area between cylindrical cells is smaller, heat transfer takes place among cells by conduction and radiation in the air gaps. The critical temperature for 4 cells is $153^{\circ} \mathrm{C}$, which is still very high compared with ambient temperature. However, when cells are stacked in warehouses or shipped in cargoes, the number of cells is relatively large, and therefore, based on this critical ambient trend, cell self-heating ignition could happen and lead to fires.

\subsection{Effective Kinetics and Thermal Properties}

In order to quantify the effective kinetics and thermal properties, we assume that the boundary condition is $T_{s}=T_{a}$, which is a good assumption in this work as the temperature of the cell is approximately steady before ignition, as shown in Fig. 4. 


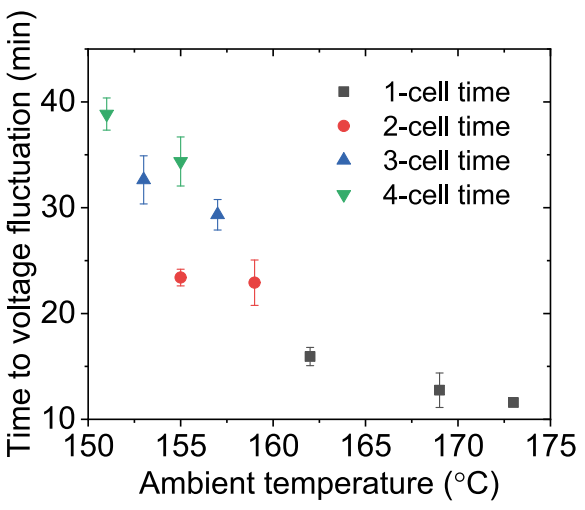

(a) Time to $1^{\text {st }}$ voltage fluctuations.

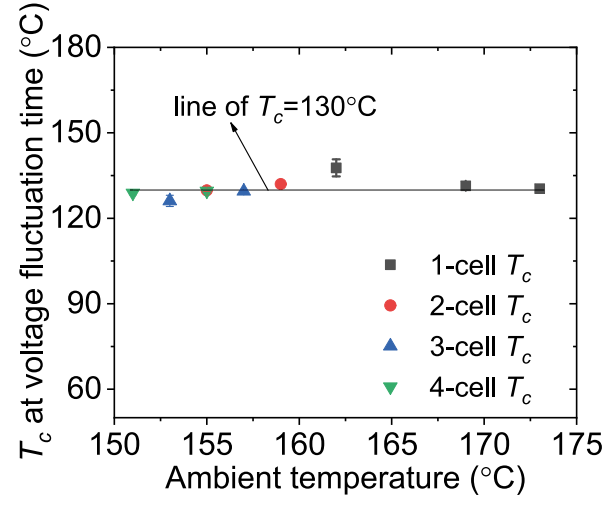

(b) $T_{c}$ at the time $1^{\text {st }}$ voltage fluctuations.

Figure 7. (a) The time to voltage fluctuation of 1-4 cell experiments, and (b) the cell temperature at that time. Cell temperatures were all around $130^{\circ} \mathrm{C}$, which is the onset temperature of side reactions.

Using the critical ignition temperatures for 1-4 cells from Fig. 9, a figure of $\ln \left(\delta_{c} T_{a}^{2} / L^{2}\right)$ vs $1000 / T_{a}$ is plotted. The best linear fit is calculated in the figure with an R-squared value of 0.981 . Figure 10 shows a typical Frank-Kamenetskii plot, which validates that the assumptions of Frank-Kamenetskii theory and one-step global Arrhenius reactions can be applied. The Frank-Kamenetskii plot also confirms that the ignition is caused by self-heating.

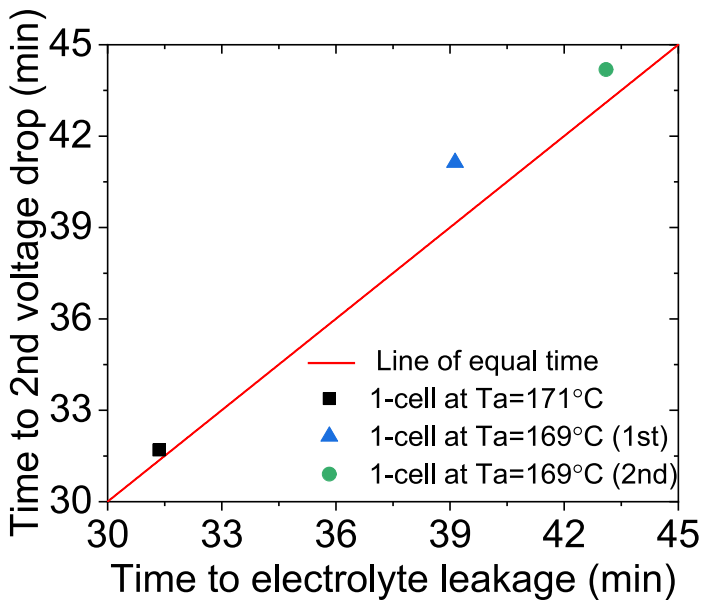

Figure 8. Relationship between time to electrolyte leakage and time to the 2nd voltage drop of three 1 -cell experiments. Time to electrolyte leakage was always slightly smaller than time to the 2 nd voltage drop, which shows electrolyte leakage can lead to the internal short circuit of cells. 


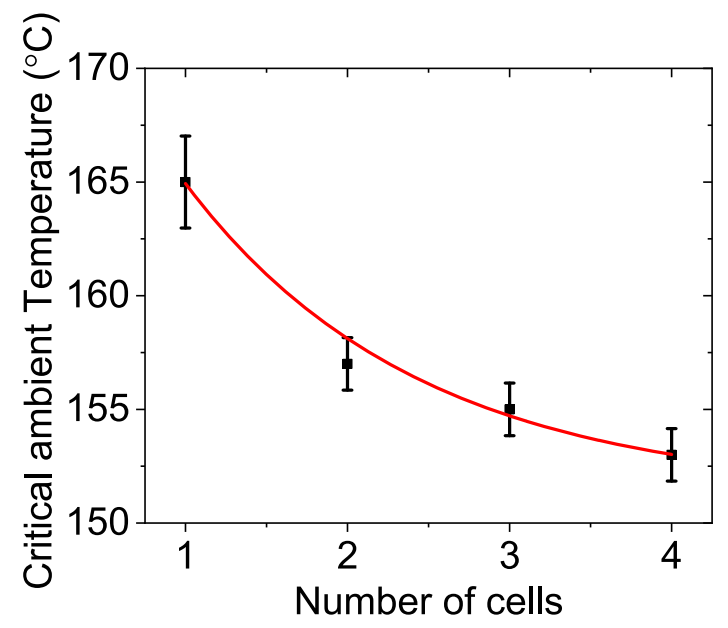

Figure 9. The critical ignition temperature identified for different
number of cells. The temperature values of $1,2,3$ and 4 batteries
are $165.5 \pm 3^{\circ} \mathrm{C}, 157 \pm 2^{\circ} \mathrm{C}, 155 \pm 2^{\circ} \mathrm{C}$ and $153 \pm 2^{\circ} \mathrm{C}$,
respectively.

The slope of the straight line corresponds to $-\frac{E}{R}$, while the y-intercept is $\ln \left(\frac{E}{R} \cdot \frac{f \Delta H_{c}}{k}\right)$. The effective conductivity $k$ of cells is highly related to cathode materials [33]. In terms of $\mathrm{LiCoO}_{2}$ cathode material, the effective conductivity $k$ is 1.08 $\mathrm{W} / \mathrm{mK}$ [33]. Based on this, the effective kinetics and thermal properties of the cell are extracted, as shown in Table 5. The errors are also shown in the table using the fits that give the highest and the lowest possible effective kinetics and thermal properties from the experimental data. These data we found in this work can contribute to predicting the cell self-heating ignition behaviour.

The kinetics we quantified are for $30 \%$ SOC, and the effective kinetics and thermophysical properties will differ if the same LIB has a higher SOC. Previous studies $[19,30]$ show a LIB has higher reactivity when its SOC is larger, and hence a LIB with higher SOC is more likely to self-ignite.

\section{Upscaling Study}

In order to predict self-heating ignition of the cells used in this work at lower ambient temperatures, the properties in Table 5 are employed in the FrankKamenetskii theory to upscale the laboratory results. In these predictions, we use 1-step effective kinetics of the cell. This method is widely used to predict self-heating phenomenon [8, 12]. The 1-step effective kinetics quantified from FrankKamenetskii theory includes the effect of multi-step kinetics, and the prediction based on effective kinetics will need to be validated when large-scale experiments become available. This upscaling result assumes cells are stacked into a cube so 


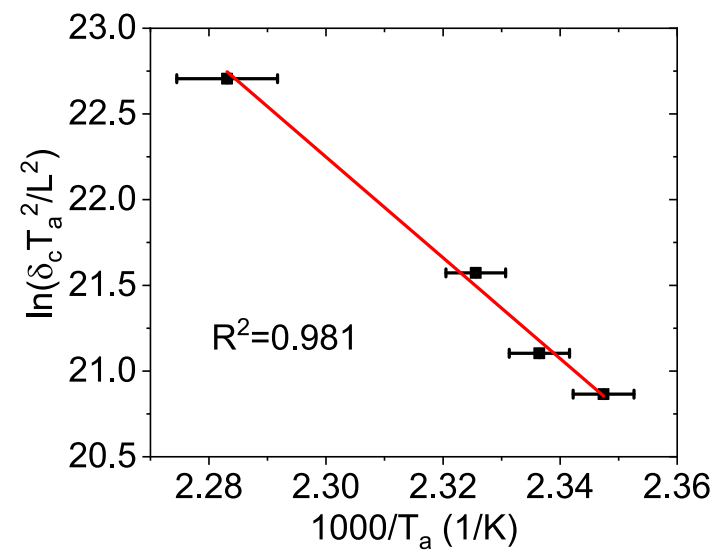

Figure 10. Frank-Kamenetskii plot for cells with LiCoO $\mathrm{O}_{2}$ cathode material. A linear fit is plotted in order to extract the effective kinetics and thermophysical parameters.

that the characteristic length equals to the ratio of volume to area and the $\delta_{c}=2.52$.

Figure 11 shows the 1D upscaled results for the $\mathrm{LiCoO}_{2}$ cell at $30 \%$ SOC. The critical temperature decreases significantly as the ratio of volume to area increases. For a 1000 Litre recycle bin (with a characteristic length of $0.5 \mathrm{~m}$ ), a size commonly used for used LIBs collection, critical self-heating ignition temperature is $114^{\circ} \mathrm{C}\left( \pm 11^{\circ} \mathrm{C}\right)$, which is $50^{\circ} \mathrm{C}$ lower than that for a single cell. As LIBs in a recycle bin could be damaged and not pristine, the critical self-heating ignition temperature could be much smaller than this prediction.

According to results in Fig. 11, even this LIB type at 30\% SOC can become hazardous at the highest credible ambient temperature of $40^{\circ} \mathrm{C}$ when its volume to area is higher than $52 \mathrm{~m}$. But it is unlikely to happen when this LIB is free from manufacturing flaws or defects, because a cube with a side length of $52 \mathrm{~m}$ is far greater than realistic value even for large rack storage. However, other LIB types or this type but with manufacturing defects can become a hazard if their self-heating reactivity is higher. Additionally, the SOC in this study is only $30 \%$, and the

\section{Table 5}

\section{Effective Activation Energy $E$ and $\ln \left(\frac{\Delta H_{c} f E}{R k}\right)$ of the Cell at $30 \%$ SOC Extracted from Frank-Kamenetskii Plot}

\begin{tabular}{lllr}
\hline$k(\mathrm{~W} / \mathrm{m} \mathrm{K})$ & $E(\mathrm{~kJ} / \mathrm{mol})(-$ error, + error $)$ & $\ln \left(\frac{\Delta H_{c} f E}{R k}\right)\left(\mathrm{K}^{2} / \mathrm{m}^{2}\right)(-$ error, + error $)$ & $R^{2}$ \\
\hline $1.08[33]$ & 230.78 & 86.03 & 0.981 \\
& $(-38.97,+83.40)$ & $(-16.72,+23.34)$ & \\
\hline
\end{tabular}




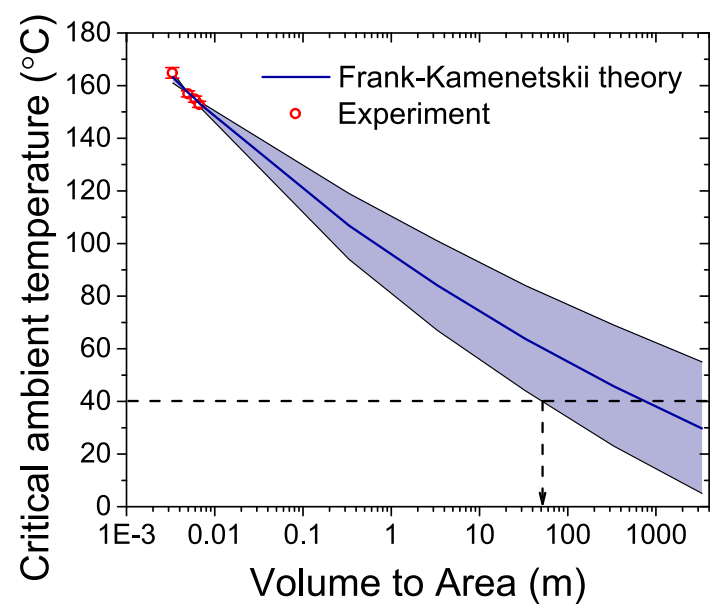

\section{Figure 11. Upscaled results of LB used in this work based on Frank- Kamenetskii theory. Uncertainty (the maximum and minimum ignition temperatures) is represented by the shaded regions for based on experimental errors (Table 5).}

critical temperature of self-heating ignition may decrease with increasing SOC, as higher SOC potentially increases the reactivity of the LIB.

The upscaled results in Fig. 11 are only for the cells, not including the effects of packaging and boxes for storage, in which LIBs will be further insulated using separations and cushions, which could decrease the critical temperature of selfheating ignition [28].

This study presents: (i) an experimental proof that LIB self-heating during storage is possible and likelihood increases with the size of the ensemble, (ii) a method to upscale laboratory experiments to study self-heating of any battery types, and (iii) evidence that the cell used in this work at 30\% SOC will not self-heat to ignition even at large scales when it is free from manufacturing flaws.

\section{Conclusions}

In this study, the effect of the number of cells on the possibility of self-heating ignition of LIBs has been investigated using oven experiments. The Sanyo prismatic $\mathrm{LiCoO}_{2}$ cells at $30 \%$ SOC were used in the experiments. Results show that self-heating ignition behaviour has three stages: heating up, self-heating, and thermal runaway. A previous study showed the critical ignition temperature for one $18650 \mathrm{LiCoO}_{2}$ cell was $155^{\circ} \mathrm{C}$ [17]. However, this study has found that the critical ignition temperature decreases as number of cells increases, which implies selfheating ignition is possible for large LIB ensembles. As the number of cells increases from 1 to 4 , the critical ambient temperature for self-heating ignition decreases from $165.5^{\circ} \mathrm{C}$ to $153^{\circ} \mathrm{C}$. A Frank-Kamenetskii analysis using these critical temperatures shows a very good linear fit between thermal properties and inverse critical 
ambient temperature with an R-squared value of 0.981 , which confirms this is selfheating ignition. The effective kinetics $E$ is $230.78 \mathrm{~kJ} / \mathrm{mol}$ and effective thermal properties $\ln \left(\frac{\Delta H_{c} f E}{R k}\right)$ is $86.03 \mathrm{~K}^{2} / \mathrm{m}^{2}$. These parameters are then used in the prediction of self-heating ignition of the cells during storage. Upscaling results show that this specific LIB type at $30 \%$ SOC is not particularly hazardous in terms of self-heating because the critical ambient temperature is high and safe enough. However, other LIB types with defects, higher SOC or being recycled could have a much larger reactivity. These LIBs could self-heat to ignition when they are stacked in a large enough ensemble during storage or transport. This work provides the first experimental study on self-heating ignition of LIBs in open circuit, contributing to understanding and predicting the onset of self-heating ignition of LIBs.

\section{Acknowledgements}

The authors would like to thank the support from China Scholarship Council (CSC) to Xuanze He and Zhenwen Hu. Many thanks to Dr Gregory Offer, Dr Yatish Patel, Yan Zhao and Eirik Christensen (Imperial College London) for their advice and help, and to Dr Jingwu Wang and Yang Peng (University of Science and Technology of China) for their help with the experiments.

\section{Open Access}

This article is licensed under a Creative Commons Attribution 4.0 International License, which permits use, sharing, adaptation, distribution and reproduction in any medium or format, as long as you give appropriate credit to the original author(s) and the source, provide a link to the Creative Commons licence, and indicate if changes were made. The images or other third party material in this article are included in the article's Creative Commons licence, unless indicated otherwise in a credit line to the material. If material is not included in the article's Creative Commons licence and your intended use is not permitted by statutory regulation or exceeds the permitted use, you will need to obtain permission directly from the copyright holder. To view a copy of this licence, visit http://creat ivecommons.org/licenses/by $/ 4.0 /$.

\section{References}

1. Grand view research (2017) Lithium-ion battery market worth $\$ 93.1$ billion by 2025 CAGR: $17.0 \%$ ". https://www.grandviewresearch.com/press-release/global-lithium-ion-b attery-market

2. Sun P et al (2020) A review of battery fires in electric vehicles. Fire Technol . https:// doi.org/10.1016/j.pecs.2020.100832 
3. Williard $\mathrm{N}$ et al (2013) Lessons learned from the 787 Dreamliner issue on lithium-ion battery reliability. Energies 6(9):4682-4695. https://doi.org/10.3390/en6094682

4. Feng $X$ et al (2018) Thermal runaway mechanism of lithium ion battery for electric vehicles: a review. Energy Storage Mater 10:246-267. https://doi.org/10.1016/ j.ensm.2017.05.013

5. Aircraft incident report: auxiliary power unit battery fire, Japan airlines Boeing 787, JA 829 J, Boston, Massachusetts, 7 January 2013. National Transportation Safety Board, DC, Rep. No. PB2014-108867, 21 November 2014

6. Maleki Hossein, Howard Jason N (2009) Internal short circuit in Li-ion cells. J Power Sources 191(2):568-574. https://doi.org/10.1016/j.jpowsour.2009.02.070

7. Liu $X$ et al (2018) Thermal runaway of lithium-ion batteries without internal short circuit. Joule 2(10):2047-2064. https://doi.org/10.1016/j.joule.2018.06.015

8. Babrauskas Vytenis (2003) Ignition handbook, 318Fire Science Publishers, Issaquah

9. Bowes PC (1984) Self-heating: evaluating and controlling the hazards. HMSO, London

10. Sun Q et al (2020) Assessment on thermal hazards of reactive chemicals in industry: state of the art and perspectives. Prog Energy Combust Sci 78:100832. https://doi.org/ $10.1016 /$ j.pecs. 2020.100832

11. Joshi KA et al (2012) An experimental study of coal dust ignition in wedge shaped hot plate configurations. Combust Flame 159(1):376-384. https://doi.org/10.1016/j.combustflame.2011.06.003

12. Restuccia F et al (2017) Self-heating behavior and ignition of shale rock. Combust Flame 176:213-219. https://doi.org/10.1016/j.combustflame.2016.09.025

13. Maleki $\mathrm{H}$ et al (1999) Thermal stability studies of Li-ion cells and components. J Electrochem Soc 146(9):3224-3229. https://doi.org/10.1149/1.1392458

14. Wang $Q$ et al (2007) Thermal stability of delithiated $\mathrm{LiMn}_{2} \mathrm{O}_{4}$ with electrolyte for lithium-ion batteries. J Electrochem Soc 154(4):A263-A267. https://doi.org/10.1149/ 1.2433698

15. Wang Q et al (2012) Thermal runaway caused fire and explosion of lithium ion battery. J Power Sources 208:210-224. https://doi.org/10.1016/j.jpowsour.2012.02.038

16. MacNeil DD, Dahn JR (2001) Test of reaction kinetics using both differential scanning and accelerating rate calorimetries as applied to the reaction of $\mathrm{Li} \times \mathrm{CoO} 2$ in non-aqueous electrolyte. J Phys Chem A 105(18):4430-4439. https://doi.org/10.1021/jp001187j

17. Hatchard TD et al (2001) Thermal model of cylindrical and prismatic lithium-ion cells. J Electrochem Soc 148(7):A755-A761. https://doi.org/10.1149/1.1377592

18. Tobishima S, Yamaki J (1999) A consideration of lithium cell safety. J Power Sources 81:882-886. https://doi.org/10.1016/S0378-7753(98)00240-7

19. Roth EP et al (2004) Thermal abuse performance of high-power 18650 Li-ion cells. J Power Sources 128(2):308-318. https://doi.org/10.1016/j.jpowsour.2003.09.068

20. Mendoza Hernandez OS et al (2015) Cathode material comparison of thermal runaway behavior of Li-ion cells at different state of charges including over charge. J Power Sources 280:499-504. https://doi.org/10.1016/j.jpowsour.2015.01.143

21. Larsson F et al (2018) Gas explosions and thermal runaways during external heating abuse of commercial lithium-ion graphite- $\mathrm{LiCoO}_{2}$ cells at different levels of ageing. $\mathbf{J}$ Power Sources 373:220-231. https://doi.org/10.1016/j.jpowsour.2017.10.085

22. Santhanagopalan S et al (2009) Analysis of internal short-circuit in a lithium ion cell. J Power Sources 194:550-557. https://doi.org/10.1016/j.jpowsour.2009.05.002

23. Orendorff CJ et al (2011) Experimental triggers for internal short circuits in lithium-ion cells. J Power Sources 196:6554-6558. https://doi.org/10.1016/j.jpowsour.2011.03.035

24. Feng $X$ et al (2016) Online internal short circuit detection for a large format lithium ion battery. Appl Energy 161:168-180. https://doi.org/10.1016/j.apenergy.2015.10.019 
25. Peifeng Huang et al (2019) Non-dimensional analysis of the criticality of Li-ion battery thermal runaway behavior. J Hazard Mater 369:268-278. https://doi.org/10.1016/j.jhazmat.2019.01.049

26. Peifeng Huang et al (2016) Experimental and modeling analysis of thermal runaway propagation over the large format energy storage battery module with Li4Ti5O12 anode. Appl Energy 183:659-673. https://doi.org/10.1016/j.apenergy.2016.08.160

27. Shah K et al (2016) Experimental and theoretical analysis of a method to predict thermal runaway in Li-ion cells. J Power Sources 330:167-174. https://doi.org/10.1016/ j.jpowsour.2016.08.133

28. Hu Z et al (2020) Numerical study of self-heating ignition of a box of lithium ion batteries during storage. Fire Technol . https://doi.org/10.1007/s10694-020-00998-8

29. Wen C-Y et al (2012) Thermal runaway features of 18650 lithium-ion batteries for LiFePO4 cathode material by DSC and VSP2. J Therm Anal Calorim 109(3):12971302. https://doi.org/10.1007/s10973-012-2573-2

30. Said AO et al (2019) Simultaneous measurement of multiple thermal hazards associated with a failure of prismatic lithium ion battery. Proc Combust Inst 37(3):4173-4180. https://doi.org/10.1016/j.proci.2018.05.066

31. Gray B (2002) Spontaneous combustion and self-heating, 3rd edn. In: DiNenno PJ (ed) SFPE handbook of fire protection engineering, pp 211-228

32. Incropera FP et al (2007) Fundamentals of heat and mass transfer. Wiley, Hoboken

33. Werner $\mathrm{D}$ et al (2017) Thermal conductivity of Li-ion batteries and their electrode configurations - a novel combination of modelling and experimental approach. J Power Sources 364:72-83. https://doi.org/10.1016/j.jpowsour.2017.07.105

34. Utsunomiya Takashi et al (2011) Self-discharge behavior and its temperature dependence of carbon electrodes in lithium-ion batteries. J Power Sources 196:8598-8603. https://doi.org/10.1016/j.jpowsour.2011.05.066

Publisher's Note Springer Nature remains neutral with regard to jurisdictional claims in published maps and institutional affiliations. 